\title{
Effect of dietary bile extracts on serum response of astaxanthin in rainbow trout (Oncorhynchus mykiss): a preliminary study
}

\author{
M.M. MENDES-PINTO ${ }^{1}$, G. CHOUBERT ${ }^{2}$ \& R. MORAIS ${ }^{1}$ \\ ${ }^{1}$ Escola Superior de Biotecnologia, Universidade Católica Portuguesa, Rua Dr. António Bernardino de Almeida, Porto, Portugal; \\ ${ }^{2}$ Unité Mixte Nutrition, Aquaculture et Génomique, INRA, Station d'Hydrobiologie, Saint Pée-sur-Nivelle, France
}

\begin{abstract}
Effects of porcine bile extracts added at three different dietary concentrations 0,10 and $20 \mathrm{~g} \mathrm{~kg}^{-1}$ were studied on astaxanthin serum concentration in rainbow trout (mean weight $200 \pm 7 \mathrm{~g}$ ). Astaxanthin from micro-algae Haematococcus pluvialis and synthetic astaxanthin (CAROPHYLL ${ }^{\circledR}$ pink) were incorporated in diets of rainbow trout at a rate of $100 \mathrm{mg}$ astaxanthin $\mathrm{kg}^{-1}$ of feed. Fish were hand fed twice a day. After 5 days of feeding there was a significant effect of the pigment source on the ratio (total blood astaxanthin per unit body weight to cumulative astaxanthin intake per unit body weight). Trout receiving synthetic astaxanthin showed a significantly $(P<0.05)$ higher ratio than trout fed algal astaxanthin. Increasing dietary bile extract did not lead to produce any effect on this ratio. The power of the statistical analysis is discussed. Therefore, the interaction (pigment source $\times$ dietary bile concentration) showed no more effect.
\end{abstract}

KEY wORDS: astaxanthin, bile extracts, Haematococcus pluvialis, pigmentation, serum, trout

Correspondence: Georges Choubert, Unité Mixte Nutrition, Aquaculture et Génomique, INRA, Station d'Hydrobiologie, 64310 Saint Pée-sur-Nivelle, France.E-mail: choubert@st-pee.inra.fr

\section{Introduction}

Astaxanthin is widespread in nature and is the main pigment in the marine environment. As astaxanthin cannot be synthesized de novo by fish, especially salmonids, its concentration in the flesh depends on adequate ingestion and efficient intestinal absorption from exogenous sources. In the wild, fish obtain astaxanthin from prey while in intensive culture salmonid feed must be supplemented with astaxanthin to enhance their natural pigmentation (Choubert et al. 1995; Choubert \& Storebakken 1996).

Haematococcus pluvialis is a fresh water unicellular green micro-alga which form cysts and accumulate massive amounts of astaxanthin in its cytoplasm under certain stress conditions (Goodwin \& Jamirkon 1954; Borowitzka et al. 1991; Boussiba et al. 1992) and its use for pigmentation in aquaculture has been proposed for many years. However, the effect of feeding algal astaxanthin has been reported in the past showing a lower trout flesh pigmentation when comparing with synthetic astaxanthin (Sommer et al. 1991, 1992; Choubert \& Henrich 1993; White et al. 2002).

Carotenoids are lipid-soluble compounds. Their absorption into the intestinal mucosal cells is considered to occur by passive diffusion (Deming \& Erdman 1999). Carotenoid absorption requires solubilization into mixed micellar solutions before efficient absorption can occur (El-Gorab et al. 1975). Mixed micelles are formed from bile salts and lipolytic products of dietary fat during intestinal absorption (Deming \& Erdman 1999). The bile by its detergent properties enhances emulsion formation of fat and then assists in the digestion and absorption of carotenoid content herein (Gagnon \& Dawson 1968; Klaüi \& Bauernfeind 1981). Therefore, one can expect an enhancement in carotenoid absorption caused by bile salt supplementation into the diets.

The goal of this study was to evaluate the effect of incremental increases in the diets porcine bile concentrations on astaxanthin concentration in the serum of fish fed either synthetic astaxanthin or algal astaxanthin from Haematococcus pluvialis. 
disposable needles (Becton Dickinson France, Le Pont de Claix, France). Approximately $2.0 \mathrm{~mL}$ of blood sample per fish was held overnight at $+4{ }^{\circ} \mathrm{C}$ for clotting. Serum was removed after sample centrifugation at $2000 \times \boldsymbol{g}$ (Model T52.1, MLW, Engelsdorf, Germany) for $5 \mathrm{~min}$.

Serum $(0.5 \mathrm{~mL})$ was vortexed with $1 \mathrm{~mL}$ ethanol $\left(95^{\circ} \mathrm{C}\right)$ for $30 \mathrm{~s}$, followed by addition of $1 \mathrm{~mL} n$-hexane (both from Carlo Erba, Rodano, Italy); the mixture was vortexed for $1 \mathrm{~min}$. The $n$-hexane was separated by centrifugation at $2000 \times \boldsymbol{g}$ for $5 \mathrm{~min}$. The process was repeated twice to complete astaxanthin extraction. Absorbance was measured at $480 \mathrm{~nm}$ in $n$-hexane using a UV-Visible spectrophotometer (UV-160A; Shimadzu, Tokyo, Japan). Astaxanthin concentration was calculated using a specific extinction coefficient of 2100 in $n$-hexane (Weber 1988).

For carotenoid extraction, micro-algal biomass was prior mechanically ground during $5 \mathrm{~min}$ (grinder Dangoumeau). Then carotenoids and lipids were extracted using the method of Folch et al. (1957). Determination of total carotenoids content was made by UV-Visible spectrophotometry. Extracts were resuspended in $20 \mathrm{~mL}$ dichloromethane and the specific extinction coefficient used was 2100 in dichloromethane (Weber 1988). All calculations were made on a dry matter basis. Algal carotenoid separation was made by TLC on pre-coated silica gel H60 TLC plates $20 \times 20 \mathrm{~cm}$ (Merck, Darmstad, Germany) using as solvent system acetone: $n$-hexane $3: 7$ (v/v) (Kobayashi et al. 1991) at room temperature. In a diffused light different TLC bands corresponding to free, mono and diester astaxanthin (according to their $R_{\mathrm{f}}$ values) were scrapped off, eluted with acetone and vacuum filtered. Each band extract was dried under vacuum in a rotary evaporator (RE-121 mod.; Büchi Laboratoriums Technik, Flawil, Switzerland) and resuspended in dichloromethane for spectrophotometric determination.

For diets containing algae, astaxanthin was analysed after lipids extraction (Folch et al. 1957) and quantified by spectrophotometry as described above. For diets containing synthetic astaxanthin the method of Schüep \& Schierle (1995) was performed.

Due to the differences in amounts of astaxanthin in the test diets, data of astaxanthin concentrations in the serum were calculated as ratio (total blood astaxanthin per unit body weight to cumulative astaxanthin intake per unit body weight). A mean whole trout blood volume of $38 \mathrm{~mL} \mathrm{~kg}^{-1}$ at a water temperature of $16^{\circ} \mathrm{C}$ was used for calculation according to Nikinmara et al. (1981). The results are given as mean \pm SD. Data were subjected to analysis of variance and Duncan's multiple range test using the SAS-GLM procedure (SAS 1989). Statistical significances are indicated for $P<0.05$ (Zar 1984).

\section{Results}

Total amount of carotenoid pigments of micro-algae Haematococcus pluvialis was $32 \mathrm{mg} \mathrm{kg}^{-1}$ on a dry weight basis of which keto-carotenoids accounted for 98.6\%. Algal pigments are reported in Table 2. Astaxanthin monoester was the major carotenoid pigment of the algae and accounted for more than $80 \%$ of the total carotenoid concentration. Diets containing algae were formulated taking into account their astaxanthin profile. On this basis astaxanthin intake by fish was $0.32 \pm 0.04 \mathrm{mg}$ astaxanthin $\mathrm{day}^{-1}$ for trout fed algae supplemented diets and $0.37 \pm 0.03 \mathrm{mg}$ astaxanthin $\mathrm{day}^{-1}$ for trout fed synthetic astaxanthin supplemented diets.

Ratio (total blood astaxanthin per unit body weight to cumulative astaxanthin intake per unit body weight) in groups of rainbow trout fed the six test diets are shown in Table 3. After 5 days of feeding there was a significant effect of the pigment source on the ratio [total blood astaxanthin per unit body weight to cumulative astaxanthin intake per unit body weight]. Trout receiving synthetic astaxanthin showed a significantly $(P<0.05)$ higher ratio than trout fed algal astaxanthin. Increasing dietary bile extract did not lead to produce any effect on this ratio. Therefore, the interaction (pigment source $\times$ dietary bile concentration) showed no more effect.

\section{Discussion}

The astaxanthin content analysed in the algae is consistent with that reported in previous works (Grung et al. 1992; Lorenz \& Cysewski 2000; Mendes-Pinto et al. 2001). Variations in carotenoid composition, especially mono and di-ester fractions, seem to be the result of different culture conditions and to depend on the age of the culture (Harker et al. 1996). However, this study confirmed that the major carotenoid pigment was astaxanthin in an amount as high as $98.6 \%$ of total carotenoids.

The micro-algae Haematococcus pluvialis occur in an encysted form surrounded by a thick cell wall, which may impede astaxanthin absorption by fish (Choubert \& Henrich 1993). Therefore, an inefficient algae cell wall disruption leads to a limitation of its bioavailability (Sommer et al. 1991, 1992; Choubert \& Henrich 1993). That is why algae

Table 2 Carotenoid pigments of the alga Haematococcus pluvialis

\begin{tabular}{lc}
\hline Carotenoid & \% Total carotenoids DM \\
\hline Astaxanthin di-ester & 17.2 \\
Astaxanthin mono-ester & 81.3 \\
Astaxanthin free form & 1.4 \\
\hline
\end{tabular}

${ }^{1} \mathrm{DM}$ : dry matter basis. 


\begin{tabular}{lcc}
\hline $\begin{array}{l}\text { Dietary bile } \\
\text { concentration }\left(\mathrm{g} \mathrm{kg}^{-1}\right)\end{array}$ & $\begin{array}{l}\text { BA/CAl algae } \\
\text { astaxanthin }\end{array}$ & $\begin{array}{c}\text { BA/CAl synthetic } \\
\text { astaxanthin }\end{array}$ \\
\hline 0 & $1.74 \pm 0.68^{\mathrm{b} * 2}$ & $1.97 \pm 0.67^{\mathrm{a} *}$ \\
10 & $1.35 \pm 0.54^{\mathrm{b} *}$ & $1.82 \pm 0.34^{\mathrm{a} *}$ \\
20 & $1.01 \pm 0.41^{\mathrm{b} *}$ & $1.97 \pm 0.74^{\mathrm{a} *}$ \\
Significance & Mean square & $P$-values \\
\hline Pigment source (PS) & 4.6710 & 0.0004 \\
Dietary bile & 0.7256 & 0.1226 \\
concentration (BC) & & 0.1403 \\
\hline Interaction (PS $\times \mathrm{BC})$ & 0.6772 & \\
\hline
\end{tabular}

Table 3 Changes in ratio: blood astaxanthin per unit body weight/ cumulative astaxanthin intake per unit body weight $(\mathrm{BA} / \mathrm{CAI})$ in groups $(n=2)$ of rainbow trout $(n=10)$ each fed the six test diets for 5 days

${ }^{1}$ Data are mean $\pm S D$.

${ }^{2}$ Within a row means with different superscript are significantly different, Duncan's multiple range test, $P<0.05$. Within a column means with common asterisk are not significantly different, Duncan's multiple range test, $P<0.05$.

biomass was carefully ground before its addition to the diets. However this grinding step may explain the differences observed in the astaxanthin concentrations between the two series of test diets.

Fish were fed for 5 days to assure that astaxanthin serum concentration was maximum given the observation that a plateau of concentration is reached after one day of astaxanthin intake (Choubert et al. 1994). In these conditions mean serum astaxanthin concentrations can be used as an indicator of astaxanthin availability (Storebakken \& Goswami 1996).

Despite the fact that there was a slight difference in amounts of astaxanthin in the test diets, our results showed that when no bile salts were added to the fish diet, serum astaxanthin concentrations of trout fed the diet supplemented with algae Haematococcus pluvialis were lower than those of trout fed the diet supplemented with synthetic astaxanthin. Algal astaxanthin is mostly in ester form (Renstrøm et al. 1981) while synthetic astaxanthin is in the free form (Klaüi \& Bauernfeind 1981). Studies on absorption of ester/free forms of astaxanthin led to contradictory results: some authors claimed that the free form is better absorbed than the ester form (Foss et al. 1987; Storebakken et al. 1987; Choubert \& Henrich 1993; White et al. 2002), some others reported that ester/free forms are equally absorbed (Barbosa et al. 1999; Bowen et al. 2002; White et al. 2002), lastly others observed that the ester form is better absorbed than the free form when the lipid level of the diet is low (Barbosa et al. 1999). From analogy with lutein recent data suggest that the bioavailability of ester form is not significantly different from that of free form (Bowen et al. 2002).

Blood astaxanthin concentration of trout fed diet supplemented with either algal or synthetic astaxanthin seemed not affected by an incremental increase of bile extracts in the diet. This was unexpected since it has been reported that bile extracts enhanced the absorption of $\beta$-carotene in rats (Gagnon \& Dawson 1968) or human (Furr \& Clark 1997). A possible biological explanation would be that bile concentrations used in this experiment were not sufficient. Based on the molecular weight of the glycodeoxycholic acid (449.6) the concentrations used were 2.427 and $4.855 \mathrm{mM}$ for bile at a rate of 10 and $20 \mathrm{~g} \mathrm{~kg}^{-1}$, respectively. In rat the uptake of $\beta$-carotene increased with increasing bile salt concentration up to 8-10 mM (El-Gorab et al. 1975). But another possible explanation would be the power of our experimental design. It is possible indeed that a real effect existed in our experiment but that no significant relationship was found because of large sampling variability or small sample size. Therefore, an a posteriori calculation was processed to evaluate the power of our analysis according to Searcy-Bernal (1994). Using from our analysis of variance $F=2.18, k=3$ and $n=2$, a value of $f=0.85$ was obtained and interpolation in the power table given by Searcy-Bernal yields a power of 0.19 . Therefore, the design of our experiment had only $19 \%$ chance of detecting any differences. In this case it can only be stated that the results obtained in our experiment to show any effect of increasing dietary bile extracts on the blood astaxanthin concentration are not conclusive.

On these basis, more powerful experiments are therefore necessary to study if added bile extracts to fish diet can enhance blood astaxanthin concentration.

\section{Acknowledgements}

We acknowledge with thanks Laurence Larroquet for her technical assistance and the technical staff of the INRA experimental fish farm of Donzacq (Landes department) for supplying the experimental animals. The authors would like 
to thank also Produits Roche France (Neuilly-sur-Seine, France) for providing CAROPHYLL® pink. M.M. MendesPinto's stay in France was made possible through the Portugal-France Scientific and Technical Cooperation Exchange Programme (ICCTI-French Embassy at Lisbon, Portugal, project 2000/417-P8).

\section{References}

Barbosa, M.J., Morais, R. \& Choubert, G. (1999) Effects of carotenoid source and dietary lipid content on blood astaxanthin concentration in rainbow trout (Oncorhynchus mykiss). Aquaculture, 176, 331-341.

Borowitzka, A.M., Huisman, M.J. \& Osborn, A.A. (1991) Culture of astaxanthin-producing green alga Haematococcus pluvialis. 1. Effects of nutrients on growth and cell type. J. Appl. Phycol., 3, 295-304.

Boussiba, S., Fan, L. \& Vonshak, A. (1992) Enhancement and determination of astaxanthin accumulation in green alga Haematococcus pluvialis. Meth. Enzymol., 213, 386-391.

Bowen, P.E., Herbst-Espinosa, M., Hussain, E.A. \& StacewiczSapuntzakis, M. (2002) Esterification does not impair lutein bioavailability in humans. J. Nutr., 132, 3668-3673.

Choubert, G. \& Henrich, O. (1993) Carotenoid pigmentation of the green alga Haematococcus pluvialis: assay on rainbow trout, Oncorhynchus mykiss, pigmentation in comparison with synthetic astaxanthin and canthaxanthin. Aquaculture, 112, 217-226.

Choubert, G. \& Storebakken, T. (1996) Digestibility of astaxanthin and canthaxanthin in rainbow trout as affected by dietary concentration, feeding rate and water salinity. Ann. Zootech., 45, 445453.

Choubert, G., Gómez, R. \& Milicua, J.C.G. (1994) Response of serum carotenoid levels to dietary astaxanthin and canthaxanthin in immature rainbow trout Oncorhynchus mykiss. Comp. Biochem. Physiol., 109A, 1001-1006.

Choubert, G., Milicua, G., Gómez, R., Sancé, S., Petit, H., NégresSadargues, G., Castillo, R. \& Trilles, J.P. (1995) Utilization of carotenoids from various sources by rainbow trout: muscle colour, carotenoid digestibility and retention. Aquacult. Intl., 3, 1-12.

Deming, D.M. \& Erdman, J.W. (1999) Mammalian carotenoid absorption and metabolism. Pure Appl. Chem., 12, 2213-2223.

El-Gorab, M., Underwood, B.A. \& Loerch, J.D. (1975) The roles of bile salts in the uptake of $\beta$-carotene and retinol by rat everted gut sacs. Bioch. Biophys. Acta, 401, 265-277.

Folch, J., Lees, M. \& Sloane-Stanley, G.H. (1957) A simple method for the isolation and purification of total lipids from animal tissues. J. Biol. Chem., 226, 497-509.

Foss, P., Storebakken, T., Austreng, E. \& Liaasen-Jensen, S. (1987) Carotenoids in diets for salmonids: V. Pigmentation of rainbow trout and sea trout with astaxanthin and astaxanthin-dipalmitate in comparison with canthaxanthin. Aquaculture, 65, 293-305.

Furr, H.C. \& Clark, R.M. (1997) Intestinal absorption and tissue distribution of carotenoids. J. Nutr. Biochem., 8, 364-377.

Gagnon, M. \& Dawson, M. (1968) The effect of bile on vitamin A absorption in the rat. Proc. Soc. Exp. Biol. Med., 127, 99-102.

Goodwin, T.W. \& Jamirkon, M. (1954) Studies in carotenogenesis: II. Carotenoid synthesis in the alga Haematococcus pluvialis. Biochem. J., 57, 376-381.
Grung, M., Da Souza, F.M.L., Borowitzka, M. \& Liaasen-Jensen, S. (1992) Algal carotenoids. 51. Secondary carotenoids. 2. Haematococcus pluvialis aplanospores as a source of (3S, 3'S)-astaxanthin esters. J. Appl. Phycol., 4, 165-171.

Harker, M., Tsavalos, A.J. \& Young, A.J. (1996) Autotrophic growth and carotenoid production of Haematococcus pluvialis in a 30 liter air-lift photobioreactor. J. Ferment. Bioeng., 82, 113-118.

Klaüi, H. \& Bauernfeind, J.C. (1981) Carotenoid as food color. In: Carotenoids as Colorants and Vitamin A Precursors (Bauernfeind, J.C. ed.), pp. 47-317. Academic Press, New York, USA.

Kobayashi, M., Kakizono, T. \& Nagai, S. (1991) Astaxanthin production by green alga Haematococcus pluvialis accompanied with morphological changes in acetate media. J. Ferment. Bioeng., 71, 335-339.

Lorenz, R.T. \& Cysewski, T. (2000) Commercial potential for Haematococcus microalgae as a natural source of astaxanthin. Tibtechnology, 18, 160-166.

Mendes-Pinto, M.M., Raposo, M.F., Bowen, J., Young, A.J. \& Morais, R. (2001) Evaluation of different cell disruption processes on encysted cells of Haematococcus pluvialis: effects on astaxanthin recovery and implications for bio-availability. J. Appl. Phycol., 13, $19-24$.

Nikinmara, M., Soivo, A. \& Railo, E. (1981) Blood volumes of Salmo gairdneri: Influence of ambient temperature. Comp. Biochem. Physiol., 69A, 767-769.

Renstrøm, B., Borch, G., Skulberg, O.M. \& Liaaen-Jensen, S. (1981). Optical purity of $\left(3 \mathrm{~S}, 3^{\prime} \mathrm{S}\right)$-astaxanthin from Haematococcus pluvialis. Phytochemistry, 20, 2561-2564.

SAS (1989) $S A S / S T A T{ }^{\circledR}$ User's Guide. Version 6, 4th edn. SAS Institute Inc., Cary, NC, USA.

Schüep, W. \& Schierle, J. (1995) Determination of stabilized, added astaxanthin in fish feeds and pre-mixes. In: Carotenoids, Vol. $1 \mathrm{~A}$. Isolation and Analysis (Britton, G., Liaaen-Jensen, S. \& Pfander, P. eds), pp. 273-276. Birkhäuser Verlag, Basel, Switzerland.

Searcy-Bernal, R. (1994) Statistical power and aquacultural research. Aquaculture, 127, 371-388.

Sommer, T.R., Potts, W.T. \& Morrisy, N.M. (1991) Utilization of microalgal astaxanthin by rainbow trout (Oncorhynchus mykiss). Aquaculture, 94, 79-88.

Sommer, T.R., Da Souza, F.M.L. \& Morrisy, N.M. (1992) Pigmentation of adult rainbow trout, Oncorhynchus mykiss, using the green alga Haematococcus pluvialis. Aquaculture, 106, 63-74.

Storebakken, T. \& Goswami, U.C. (1996) Plasma carotenoid concentration indicates the availability of dietary astaxanthin for Atlantic salmon, Salmo salar. Aquaculture, 146, 147-153.

Storebakken, T., Foss, P., Austreng, E., Liaasen-Jensen, S. \& Manz, U. (1987) Carotenoids in diets for salmonids: IV. Pigmentation of Atlantic salmon with astaxanthin, astaxanthin-dipalmitate and canthaxanthin. Aquaculture, 65, 279-292.

Weber, S. (1988) Determination of stabilized, added astaxanthin in fish feeds and premixes with HPLC. In: Analytical Methods for Vitamins and Carotenoids in Feed (Keller, H.E. ed.), Vol. 2101, pp. 59-61. Roche Publication (Animal Nutrition and health, Vitamins and Fine Chemicals Division), Basel, Switzerland.

White, D.A., Page, G.I., Swaile, J., Moody, A.J. \& Davies, S.J. (2002) Effect of esterification on the absorption of astaxanthin in rainbow trout, Oncorhynchus mykiss (Walbaum). Aquacult. Res., 33, 343-350.

Zar, J.H. (1984) Biostatistical Analysis, 2nd edn. Prentice-Hall, Englewood Cliffs, NJ, USA. 